laboratory and shop floor. The technologist finds it almost impossible to see matters through the factory worker's eyes or to talk in language that he can understand, while the worker thinks of the technologist as remote from reality, with little to contribute to day to day problems.

How refreshing then to find a book written by one with a long practised skill in craft methods who is yet enthusiastic about modern innovations, and who welcomes scientific explanation of what many prefer to regard as craft secrets. In his foreword, addressed to apprentices, journeymen, foremen and managers, $\mathrm{Mr}$ Collier writes: - This book is intended to be practical. I do not accept the idea, however, that the practical man need be totally ignorant of technology. Nor do I think that a chemist cannot learn the techniques of application connected with the materials he formulates. I believe the line between theory and practice to be arbitrary and socially undesirable. I have found most chemists to be ready to come more than half way to meet the practical man and it is to be hoped that more practical men will make the necessary effort to understand his materials and the bases upon which they are formulated". These are admirable sentiments.

Wood finishing, particularly furniture finishing, is in rapid transition from craft to technology. As firms practising it grow larger in size and fewer in number, the leisurely processes of the past are superseded. French polish is today little used, and the stage of interlinked machines, with the various steps of finishing taking place along a conveyor, is now being reached. There is a continuing tendency for the machine to take over more and more from the human operator. In all this, finishing is but following a path long since trodden by more advanced industrial procosses.

Until now the books devoted to wood finishing have been very much at the craft level, even wher they have advanced to acknowledgment of spray guns and nitrocellulose lacquers. They have been more suited to the individual worker in a small shop than to the finisher involved in a modern production plant. Now we have a book to fill this gap. While not ignoring the older methods, Collier is equally thorough in his treatment of the materials that have emerged from the laboratory in the past dozen years or so, and of the methods of application that have been developed to reduce the manpower so prodigally used by the older ones.

This is a book for everyone concerned with finishing timber for interior use. It is not one to be skimmed at a sitting, but one to be dipped into, to be read in parts, to be digested and to be consulted time and again in the future.

Rostron Hindley

\section{DEGRADING TIMBER}

\section{Timber Pests and Diseases}

By W. P. K. Findlay. (Pergamon Series of Monographs on Furniture and Timber, Vol. 5.) Pp. xi +280. (Oxford, London and New York: Pergamon Press, Ltd., 1967.) $30 s$. net.

IN this small, handy book, the author attempts to deal with all the different types of agency which can degrade timber both in the growing tree and after felling. This is an immense task and because of the very wide compass dealt with there are inevitably inequalities in treatment. As might be expected from a co-author of Decay of Timber and Its Prevention, the chapters on timber staining, timber deterioration after felling, decay in buildings, in farms and gardens, and in boats and marine works are well written with good illustrations and straightforward prescriptions for control. Other sections seem less adequate and in the chapter on "Diseases of Standing Trees", for example. stump treatment against Fomes annosus is not well explained. The sections on damage to timber caused by insects are useful summaries of information. It is somewhat surprising, however, in a book where space is at a premium and which is presumably aimed at a mainly British readership, to find eighteen pages devoted to termites.

This book is essentially one for the non-specialist and practical man and it forms a good introduction to the subject of degradation of wood in its entirety.

\section{J. S. Murray}

MYLES CROOKF

\section{ANCIENT MEDICINE}

\section{Primitive and Archaic Medicine}

By Henry E. Sigerist. (History of Medicine 1.) Pp. xxi+ 564. (London and New York: Oxford University Press, 1967.) $\$ 3.50 ; 24 s$.

THE contributions of Henry Sigerist as a medical historian are well known. After he left the Chair at Leiprig in 1925 he went to the United States, whore he subsequently occupied William H. Welch's Chair in the History of Medicine at Johns Hopkins University. By this time he had clarified his great plan for a history of medicine, global in scope; one that would place medicine in the broad setting of general history and give some indication of the vast part played by the medical sciences among the forces which have determined the progress of mankind. This is the basic explanation of his work as sot out by John Fulton in the preface to this volume.

As part of his training to approach this vast task Dr Sigerist followed his classical education with a medical degree, training in historiography, and in addition to an expert knowledge of the languages of Western Europe he devoted several years to the study of Oriental languages and also of Russian.

After fifteen years in the United States he retired at the age of 56 from the Chair at Johns Hopkins and went to live in Switzerland so as to devote his whole offorts to the eight volume history of medicine that he had planned. By the time of his death in 1957 he had completed this first volume on Primitive and Archaic Medicine and also a second volume on early Greek, Hindu and Persian Medicine that was published in 1961 .

The first edition of this present volume appeared in 1951 with hard covers. This is a notablo second edition as a paper back. In this cheaper and more popular form it will command a wide audience, especially as this republication will draw new attention to the work.

The size and comprehensiveness alone make it very difficult to write a full appraisal of such a volume. It could also be an unwise thing to attempt to particularize details of such a vast and scholarly work.

In this volume of more than 500 pages we are able to read and appreciate a unique presentation of primitive and archaic medicine and to realize that until barely a century ago much of what could be thought archaic was still practised. Indeed, there are still relics and names of primitive medicine in our daily life and work.

The outstanding feature in this volume is the presentation of medicine in Ancient Egypt. Here alone one sees how the development of medicine is intimately mixed with the passage of history itself. 'This fascinating account of Ancient Egypt and the simple clear presentation of its history are followed by an equally enthralling account of Mesopotamian medicine. Each chapter in the work is followed by an invaluable and impressive bibliography.

It is to be hoped that the second volume will in due course appear in the same form as this one. We can only regret that Dr Sigerist's death has prevented us from reading and enjoying the remaining volumes that would have completed his grand plan.
BROCK 